\title{
Empirical Evaluation of Different Classroom Spaces on Students' Perceptions of the use and Effectiveness of 1-to-1 Technology
}

\begin{abstract}
This study evaluated if different classroom layouts enacted different pedagogical uses of digital technology in a secondary schooling environment. A quasi-experimental approach facilitated by a Single Subject Research Design (SSRD) isolated the impact of two learning spaces -traditional' classrooms, and 'New Generation Learning Spaces' (NGLS), on students' and teachers' perceptions related to the effectiveness, use and value of technology as a learning tool. Results from quantitative analyses over the period of a school year indicated that the different spatial configurations did have some impact on teachers' pedagogical uses of digital technology. This impact translated to a measurable effect on how students' perceived the effectiveness of the technology. The findings of this study build on the empirical evidence of earlier work to suggest that the spatial layout of the physical learning environment can influence teacher pedagogical use of digital technology. The replication of these results has reinforced the credibility of this unique methodological approach, arguing this evaluative strategy can offer the capacity to generate much needed robust empirical data on evaluation of physical learning spaces and its impact on the use of digital technologies.
\end{abstract}

\section{Authors}

Terry BYERS. (MLI and BEd), is currently the Director of Innovation in Learning at the Anglican Church Grammar School (Churchie), Ph.D. researcher in the 2013-2016 Australian Research Council Linkage project 'Evaluating $21^{\text {st }}$ Century Learning Environments', and Research Fellow in the 2016-2019 Australian Research Council Linkage project 'Innovative Learning Environments + Teachers Change'.

Elizabeth HARTNELL-YOUNG, (Ph.D., M Ed St, MA (Urban Research and Policy), BA, Dip Ed) is an Honorary Fellow at The University of Melbourne 
Wesley IMMS, (Ph.D., MA, BEd), is currently a Associate Professor in Learning

Environments at the University of Melbourne, its Head, Visual Art and Design Education and Research Higher Degree Coordinator for Curriculum and Teaching.

\section{Introduction}

Considerable attention has identified those factors that influence the diffusion and impact of digital technology in the classroom (see Arbelaiz \& Gorospe, 2009; Bingimlas, 2009; Ertmer \& Ottenbreit-Leftwich, 2010). Besides the quantifiable issues around access, resourcing, and technical support (Bingimlas, 2009), the classroom teacher is often identified as a mediating factor in the effective uptake and utilisation (Ertmer \& Ottenbreit-Leftwich, 2010). Interestingly, the constant role of the unaltered traditional classroom layout, in which the diffusion of technology takes place, has been largely overlooked (Arbelaiz \& Gorospe, 2009; Yang \& Huang, 2015). The work of Fisher (2010), Lippman (2101) and Yang and Huang (2015) suggests that the nuances of the physical learning space can have a direct impact on the pedagogical use of digital technologies.

Given the nascent nature of this field of study, authors have established the notion of a potential misalignment between the nature of the traditional classroom layout and affordances of digital technology (Lippman, 2010; Yang \& Huang, 2015). The work of Tyack and Tobin (1994) around the inherent rules or spatial grammar of the physical learning environment, has been drawn upon to explain its mediating role in hindering or supporting change. Arbelaiz and Gorospe (2009) described how the grammar of the traditional classroom layout has dictated the often awkward physical integration and peripheral use of digital technology.

Authors have hypothesised that disrupting the spatial 'grammar' could provide a possible avenue to support digital technology to effect its claimed impact (Arbelaiz \& Gorospe, 2009; Fisher, 2010; Lippman, 2010; Yang \& Huang, 2015). However, there is a lack of systematic methodologies or empirical evidence available to evaluate this claim. 
Therefore, this study employed a quasi-experimental approach facilitated by a Single Subject Research Design (SSRD) to evaluate if different classroom layouts altered the pedagogical uses of technology in a secondary school context. The study compared student perceptions of the effectiveness and use of their personal Tablet PC device in a traditional classroom layout and a retrofitted New Generation Learning Space (NGLS). This study built upon earlier evaluations through this approach (see Byers $\&$ Imms, 2014, 2016) by extension to a larger sample and the addition of between-group comparison of cognitively matched control groups. The result is a rigorous attempt to elicit evidence pertaining to the potential impact of different spatial layouts on the use of digital technologies in a secondary schooling setting.

\section{Imposition of digital technology into traditional classrooms}

In schools, digital technology has been imposed into unaltered traditional classroom spaces that often reflect a "Pre-information Age way of thinking" (Selwyn, 2010, p. 27). This approach has privileged existing ideologies and practices, with only superficial changes “to keep up technical appearances" (Bigum \& Rowan, 2008, p. 247). In these spaces, the use of digital technology has largely sustained, and in many instances reinforced, existing behaviours and pedagogies (Ertmer \& Ottenbreit-Leftwich, 2010; Selwyn, 2010). These superficial spatial changes stem from the lack of understanding exactly how the integration of digital technology affects the physical and social conditions of the classroom setting (Lippman, 2010). Fisher (2004) suggested that this lack of understanding points to a 'deep spatial silence'. This silence is key to understanding how the salient effects of the physical learning environments enables or restricts the implementation of technologies for pedagogical gain (Fisher, 2004; Lippman, 2010).

\section{Grammar of the traditional classroom as a barrier to the pedagogical use of technology}

The form and function of the traditional classroom are one of the few constants in education (Yang \& Huang, 2015). It has been shaped, reinforced, and perpetuated by 
physical, psychological and social constructs or the grammar of schooling (Tyack \& Tobin, 1994). Like grammatical rules, Tyack and Tobin outline how these entrenched practices and structures seek to maintain the status quo, despite the potential of the envisioned change.

Through this metaphor, it can be understood why digital technologies are imposed on unchanged classrooms leading to superficial changes to pedagogies and learning experiences. A common example is the placement and use of data projectors and interactive whiteboards. Typically, these are placed at the front of the room and have reinforced the front-centre or 'fireplace' teaching position (Reynard, 2009). From this position, teachers tend to use the technology to disseminate content through a digital medium akin to a blackboard/whiteboard (Yang \& Huang, 2015). This example, while not a critique of the efficacy of this mode of instruction, typifies how the continuation of physical conditions of the classroom maintains existing pedagogies through the peripheral use of technology.

\section{The study}

The aim of this study was to evaluate if different classroom layouts enacted different pedagogical uses of technology in a secondary school context. The research questions were:

1. To what extent does the spatial change affect how students' perceived the incidence in the use of digital technology throughout the school day?

2. To what degree does the spatial change affect how students' perceived the effectiveness of digital technology as a learning tool?

3. To what extent do students attribute spatial characteristics of classrooms to the way they used digital technology in their learning and the effectiveness of that use?

4. What are the longer-term effects of the NGLS, beyond the initial spatial transition, on student perceptions of digital technology when compared to their peers (taking into account their cognitive ability) who occupy a traditional classroom on the same assessment items assessing the same subject curriculum throughout a school year? 
The hypothesis was that the NGLS layout, designed specifically with the potential provided by ubiquitous access to technology, would enact a different pedagogical use than that experienced in an unaltered traditional classroom layout.

The spaces.

The study took place within three existing buildings that accommodated Year 7, 8, and 9 (11 to 14-year-old boys) classes. Each space had a data projector and screen, with the adequate wireless infrastructure to connect student and teacher Tablet PC devices. The Windows-based devices, with a digitised stylus and several applications, enabled teachers to develop teaching resources, deliver curriculum, and assess students through multimodal artfacts (i.e. handwritten and typed text, sound/voice, and still/moving images). Synchronous connectivity enabled teachers to disseminate content and facilitate collaboration through 'teacher-whole class', 'teacher-individual student' and 'student-student' modalities of learning.

The study focused on two different classroom layouts. The first of these spaces is typical of a conventional classroom considered 'traditional' in layout (Figure 1). The fixed orientation of the room focused on the front fireplace teaching position, delineated by a teacher desk, whiteboard, and screen.

The second of these spaces were classrooms, retrofitted to constitute an NGLS in line with Fisher's (2006) three modalities of learning (teacher-centred; student-centred; and informal). Based on the work of Lippman (2010) around the alignment of technology and space, the NGLS design (Figure 1) incorporated a polycentric or multiple focal point layout. The polycentric layout sought to de-emphasise the fireplace teaching position (Reynard, 2009). The intent was to stimulate greater movement about the space and enable adaptation and flow between various learning modalities (Fisher, 2006). Such a design sought to 
remove those perceived spatial barriers that were thought to inhibit how teachers', and therefore students', used their device.
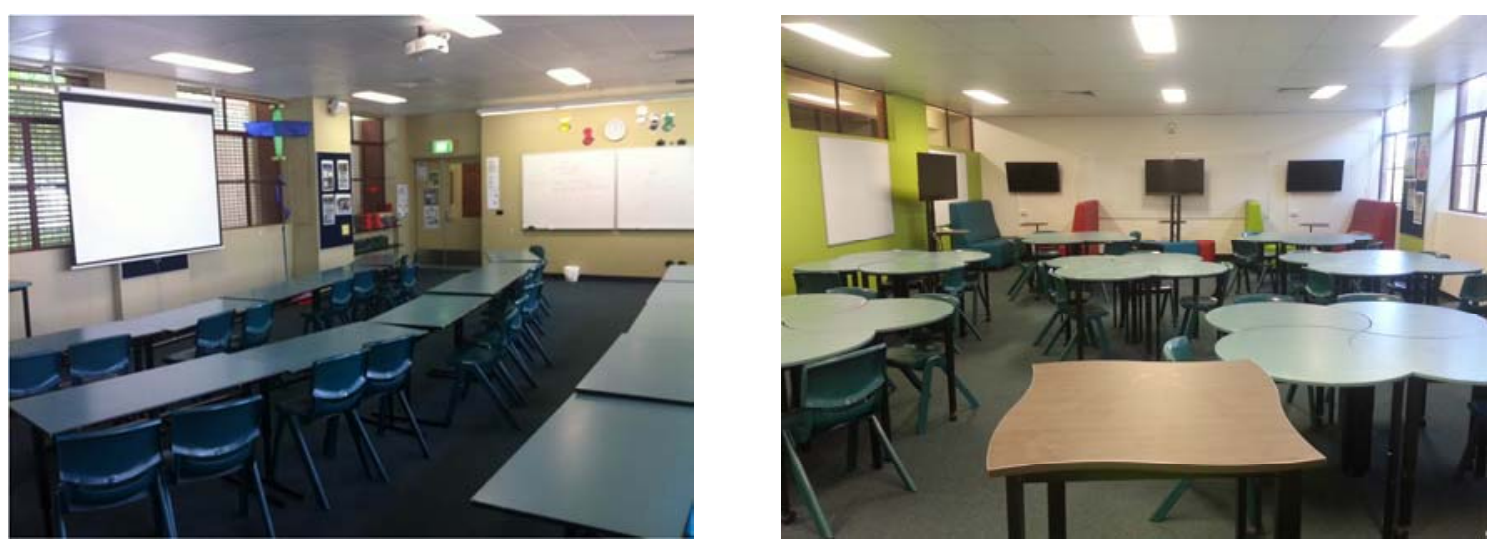

Figure 1. Comparison of Traditional (left) and New Generation Learning Space (NGLS) right) layouts.

\section{Research design.}

The quasi-experimental approach facilitated by an SSRD moderated potential impacts on external and internal validity through three design elements. First, the direct replication of the design, methods, and means of analysis of the earlier Byers and Imms $(2014,2016)$ studies improved the generality of the collective findings. Second, between-group comparisons of cognitively matched or 'like' control groups moderated the internal validity threats of assessment, curriculum, maturation, and class composition. Third, each class acted as its control, baseline, and unit of analysis, which improved the statistical power of the sample and moderated the variables of the teacher and cognitive ability.

\section{Sampling.}

The sample consisted of consenting students $(n=385)$ and teachers $(n=21)$ from 22 classes from Years 7 to 9 (Table 1). The student sample represented a participation rate of 64\%. Teacher participants, selected through convenience sampling, reflected a fair representation of year levels and subject disciplines (English, Humanities and Mathematics). 
Classes were divided into three experimental groups based on the existing timetable (Table 1). The NGLS Intervention (NI) group consisted of six classes, which spent a semester in each of the two (traditional and NGLS) classroom layouts. These classes were the focus of the within-group analysis that addressed research questions one, two and three

Six NGLS Control (NC) and ten Traditional Control (TC) classes were compared throughout a school year to address the fourth research question. These classes were the subject of between-group analysis and matched on data from the Academic Assessment Services (AAS) testing instrument. The normed and standardised AAS test was a proxy measure of cognitive ability. Independent-group t-test $(p>0.05)$ indicated that matched 'like' (high- and mixed-) ability classes were statistically similar.

Table 1.

Summary of the Sample size, Participation and Retention rates

\begin{tabular}{ccccccccccccc}
\hline Study Group & \multicolumn{3}{c}{ Sample Size } & & \multicolumn{3}{c}{ Participation Rate } & & \multicolumn{3}{c}{ Retention Rate } \\
\cline { 2 - 3 } & Yr. 7 & Yr. 8 & Yr. 9 & & Yr. 7 & Yr. 8 & Yr. 9 & & Yr. 7 & Yr. 8 & Yr. 9 \\
\hline NGLS Intervention & 37 & 21 & 58 & & $69 \%$ & $74 \%$ & $68 \%$ & $84 \%$ & $74 \%$ & $84 \%$ \\
NGLS Control & 28 & 92 & NA* & $52 \%$ & $79 \%$ & NA & $86 \%$ & $86 \%$ & NA \\
Traditional Control & 27 & 45 & 77 & $56 \%$ & $56 \%$ & $54 \%$ & $81 \%$ & $78 \%$ & $89 \%$ \\
\hline
\end{tabular}

*Not applicable

A priori power analysis $(p=0.05$ and $d=0.5)$ indicated that all but three (Year $7 \mathrm{NC}$ and TC and Year $8 \mathrm{NI}$ ) of the sample sizes were adequate for the desired statistical power (0.8). To maintain the a priori statistical power and reduce the potential for bias, a complete data set was produced through the Maximum Likelihood Estimation (MLE) (Peugh \& Enders, 2004). First, an overall Little's Missing Completely at Random (MCAR) test score greater than 0.05 (0.94) indicated that the missing data was, in fact, MCAR. Second, the MLE process produced a complete data set through the Expectation-Maximisation algorithm. 


\section{Methods.}

The research questions were addressed through an anonymous, repeated-measures student attitudinal survey and teacher focus group. The repeated measures Linking Pedagogy, Technology and Space (LPTS) consisted of five point Likert-scale items assigned to three underlying scales. Table 2 shows the independent variables and sample items for the LPTS scales. The items were derived from elements of the Tamim, Lowerison, Schmid, Bernard, and Abrami (2011) and Byers and Imms (2014, 2016) studies.

Table 2.

Descriptive Information for the LPTS Survey Digital Technology Questions

\begin{tabular}{ccc}
\hline LPTS Scale & Independent Variables & Sample Item \\
\hline Incidence in use of & Use at school & In a normal school day, how often do you use your \\
Digital Technology & Use at home & Tablet PC in class? \\
(Scale A) & Relevance & I prefer using Technology instead of a traditional \\
Effectiveness of & Flexibility & paper notebook/exercise book? \\
Digital Technology & Preference & \\
(Scale B) & Positive influence & The use of technology, in this space, has had a \\
Spatial Effect on & Effectiveness & positive influence on my learning? \\
Technology & & \\
(Scale C) &
\end{tabular}

Data analysis.

There were four distinct components to the analyses. First, post hoc Cronbach's alpha assessed the reliability of student survey responses. This determined the capacity the data of each of LPTS scale to be summed and treated as one unit for analysis.

Second, one-way repeated Analysis of Variance (RM-ANOVA) determined if a statistically significant difference existed between student attitudes in an NGLS compared to 
the traditional layout for the NI classes. Post-hoc visual analysis, effect size (Hedge's $g$ ) and partial eta squared ( $\eta 2$ ) values focused on the timing, direction, and magnitude of the spatial intervention on student LPTS survey responses. To avoid the issues of positively correlated data, adjusted Cousineau-Morey CIs were calculated as recommended by Baguley (2012).

Third, a one between- and one within-subjects factor RM-ANOVA facilitated between-group analysis of the matched NC and TC (control) classes. The analysis focused on the longitudinal effects of the different spaces on student attitudes. Concurrently, it investigated if the effect of 'novelty' influenced the within-group intervention analysis.

Four, thematic analysis of the teacher focus group. The preceding quantitative analysis informed the development of these themes. Analysis of the teachers' voice, clarified how technology was used in each layout and how this influenced trends within the quantitative analysis.

\section{Results and discussion}

The reliability of student attitudinal data.

Reliability estimates through Cronbach's alpha were calculated for each survey scale (Table 3). All estimates were in the acceptable range identified by Gliem and Gliem (2003). This supported data for each class in each scale to be summed and treated as one unit for analysis.

Table 3.

Post hoc Reliability Analysis through Cronbach's Alphas for Survey Scales

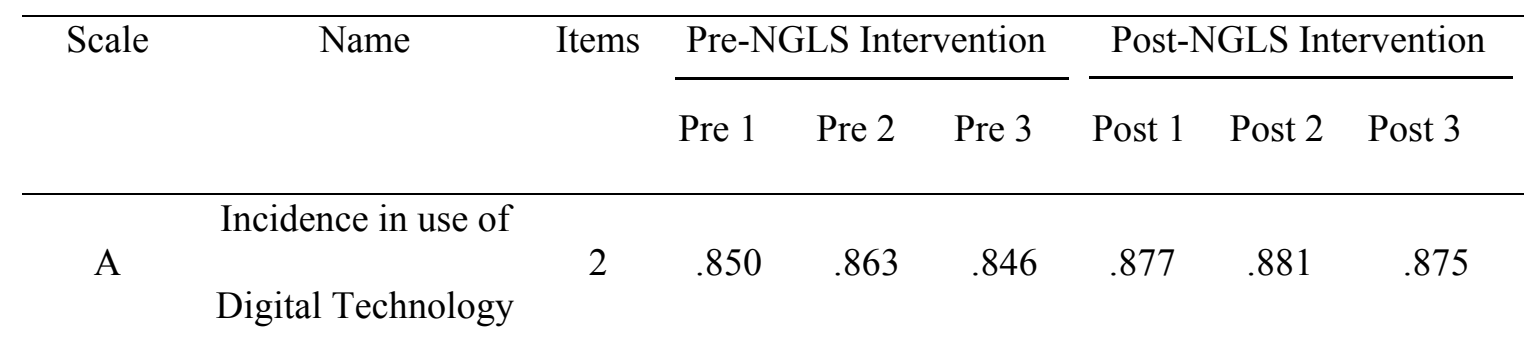




\begin{tabular}{|c|c|c|c|c|c|c|c|c|}
\hline B & $\begin{array}{c}\text { Effectiveness of } \\
\text { Digital Technology }\end{array}$ & 4 & .772 & .762 & .795 & .804 & .821 & .810 \\
\hline $\mathrm{C}$ & $\begin{array}{l}\text { Spatial Effect on } \\
\text { Technology }\end{array}$ & 2 & .806 & .824 & .850 & .837 & .813 & .856 \\
\hline
\end{tabular}

The effect of a spatial intervention on student technology usage and learning experiences.

The within-group RM-ANOVA and post hoc analysis of the six NI classes determined if statistically significant changes in student attitudes correlated with the timing of the spatial intervention. Before the RM-ANOVA, Shapiro-Wilks's statistics supported the assumption of normality. There were instances when sphericity could not be assumed, based on the calculation of Mauchly's test. Consequently, Greenhouse-Geisser-corrected values are reported.

Incidence of the use of the student device.

The RM-ANOVA (Table 4) and post hoc analysis (Table 5) of Scale A responded to the first research question. The analysis suggested that the spatial intervention did not affect the incidence of student use of their device. Post hoc visual analysis revealed that in each class, the students' indicated a consistent and high incidence ( $>50 \%)$ in the daily usage of their Tablet PC device in either spatial layout.

The effectiveness of digital technology.

The RM-ANOVA of Scale B evaluated student perceptions relating to the effectiveness of the technology in their learning. Five classes returned a significant time effect. Post hoc analysis revealed that the statistically significant effects $(p<0.05)$ for classes 8.1 and 9.1 were attributed to the timing of the intervention. For classes 7.1, 7.2, and 9.2 the visual analysis revealed the instance of latency (delayed statistical difference). 
The difference in the rate of change across this sample could be attributed to teacher environmental competency (Lackney, 2008). Lackney (2008) identified environmental comptency as the ability to utilise the affordances of the physical learning environment with their practices for pedagogical gain. Together with teacher self-efficacy in the use of digital technology as identified by Ertmer and Ottenbreit-Leftwich (2010), these instances of latency suggested that these teachers took some time before they altered their use of technology to exploit the spatial affordances of the NGLS for pedagogical gain. Whereas, the environmental competency and self-efficacy of those teachers of the classes 8.1 and 9.1 supported them to make those observable changes to their use of technology more easily, which resulted in a more immediate change in student perceptions.

Spatial effect on student perceptions about digital technology.

To answer the third research question, the RM-ANOVA evaluated responses to Scale $\mathrm{C}$, which focused on the perceived effect of a student's current learning environment on their attitudes to digital technology. The RM-ANOVAs (Table 4) and post hoc comparisons (Table 5) correlated statistically significant differences in student attitudes at the timing of the spatial intervention for classes 8.1, 9.1, 9.2, and 9.3. Like the analysis of Scale B, the post hoc analysis of class 7.2 indicated a latent statistical change.

Analysis of responses to Scale $\mathrm{C}$ suggested that students identified a considerable positive change in their use and effectiveness of digital technology during the time in the NGLS. In comparison, during their time in a more traditional layout, their responses suggested that their use of digital technology added little to their learning experiences. The evidence presented here does support the suggestions of Fisher (2010), Lippman (2010) and Yang and Huang (2015) of the plausible influence of the different spatial layouts on how digital technology is used in the classroom. 
The similarity between how specific classes responded to Scales B and C, in particular, the magnitude and nature of the change for classes 8.1 and 9.1, could further indicate the potential effect of the classroom teacher as identified by Ertmer and OttenbreitLeftwich (2010). This correlation, coupled with the instances of latency, further strengthen the confounding influence of teacher environmental competency (Lackney, 2008). Building on the work of Byers and Imms $(2014,2016)$ these findings suggest that the classroom teacher and their environmental competency and self-efficacy are key underlying contributors in how different spaces can shape the pedgogical use of technology.

Table 4.

Summary of RM-ANOVA that Measured Changes in Student Perceptions to Digital Technology through the Spatial Transformation from Traditional Classroom to NGLS

\begin{tabular}{|c|c|c|c|c|c|c|c|c|c|c|c|c|}
\hline \multirow{2}{*}{ Class } & \multicolumn{4}{|c|}{ Incidence in Use } & \multicolumn{4}{|c|}{ Effectiveness } & \multicolumn{4}{|c|}{ Effect of Space } \\
\hline & MS & $\mathrm{df}$ & $\mathrm{F}$ & $\eta^{2}$ & MS & $\mathrm{df}$ & $\mathrm{F}$ & $\eta^{2}$ & MS & $\mathrm{df}$ & $\mathrm{F}$ & $\eta^{2}$ \\
\hline 7.1 & .49 & 2.78 & .99 & .07 & 1.44 & 3.25 & $6.23 *$ & .32 & .71 & 3 & 2.30 & .15 \\
\hline 7.2 & 2.28 & 3.13 & 2.37 & .12 & 3.26 & 3.36 & $11.07 *$ & .34 & 1.98 & 3.36 & $11.07 * *$ & .24 \\
\hline 8.1 & 1.28 & 5 & $3.06^{*}$ & .12 & 5.00 & 5 & $11.58^{* *}$ & .37 & 11.98 & 3.22 & $12.17 * *$ & .38 \\
\hline 9.1 & 1.01 & 5 & $2.37 *$ & .11 & 2.48 & 5 & $11.79 * *$ & .39 & 4.49 & 5 & $13.11 * *$ & .42 \\
\hline 9.2 & .48 & 5 & .67 & .04 & 3.95 & 5 & $7.39 * *$ & .29 & 6.96 & 5 & $14.53 * *$ & .45 \\
\hline 9.3 & .63 & 2.76 & 1.06 & .05 & 1.41 & 3.80 & 1.30 & .14 & 3.13 & 3.44 & $7.24 * *$ & .28 \\
\hline
\end{tabular}

Table 5.

Post hoc Visual and Effect Size Analysis of Changes in Student Perceptions of Digital Technology as a Learning Tool through the Spatial Transformation from Traditional Classroom to NGLS 


\begin{tabular}{|c|c|c|c|c|c|c|}
\hline \multirow[t]{2}{*}{ Class } & \multicolumn{2}{|c|}{ Incidence in Use } & \multicolumn{2}{|c|}{ Effectiveness } & \multicolumn{2}{|c|}{ Effect of Space } \\
\hline & Visual & $g$ & Visual & $g$ & Visual & $g$ \\
\hline 7.1 & $N S^{a}$ & +0.13 & NS & +0.98 & NS & +0.73 \\
\hline 7.2 & $N S$ & -0.14 & $N S$ & +1.08 & $N S$ & +0.91 \\
\hline 8.1 & NS & +0.09 & $S S^{b}$ & +1.14 & SS & +1.38 \\
\hline 9.1 & $N S$ & +0.27 & SS & +1.50 & SS & +1.56 \\
\hline 9.2 & $N S$ & +0.18 & $N S$ & +1.06 & SS & +1.57 \\
\hline 9.3 & $N S$ & -0.03 & $N S$ & +0.46 & SS & +1.08 \\
\hline
\end{tabular}

Note. ${ }^{\text {a }}$ Non-statistically significant visual effect. ${ }^{\mathrm{b}}$ Statistically significant visual effect.

Evaluating the longitudinal effects of different learning spaces on attitudes to digital technology

To answer the fourth research question, between-group RM-ANOVAs of matched control classes evaluated the layout type (main effect), student attitudes (learning space and time) and the possible interaction to determine the longer-term of these effects (learning space $\mathrm{x}$ time). These comparisons focused on the impact of the different layouts, without the influence of the novelty brought by the spatial intervention. Calculated residuals indicated there were no significant outliers. Shapiro-Wilks statistics supported the assumption of normality.

Incidence of usage of the student device.

The between-group RM-ANOVA and post hoc analysis resulted in similar findings to the within-group intervention analysis. Even though the RM-ANOVA (Table 6) returned a significant time effect in four of the six comparisons, post hoc comparisons (Table ) indicated that none maintained a clear and consistent statistical difference across all measures. Like the within-group comparisons, the visual analysis revealed consistent and high daily usage of digital technology by students in this sample, replicating the findings of the Byers and Imms (2014, 2016) studies. 
The effectiveness of digital technology.

The analysis of responses to Scale B indicated that the students in an NGLS had a differing view of the effectiveness of their device from their peers in the traditional classroom. The RM-ANOVAs (Table 6), supported by post hoc analysis (Table 7), indicated a clear and consistent significant time effect (learning space $\mathrm{x}$ time) between classes: 8.2 (NC) and $8.6(\mathrm{TC}), 8.3(\mathrm{NC})$ and 8.7 (TC), and $8.5(\mathrm{NC})$ and 8.7 (TC) across the study's duration. Instances of overlapping CIs $(p>0.05)$ in the post hoc analysis of the remaining comparisons meant that these did not meet the criterion of a consistent statistical difference Comparison of between- and within-group analysis of responses to Scale B revealed that the students in the NGLS tended to have a more positive perception of the effectiveness of their device than their peers in the traditional classroom. Thereby, the replicated evidence in this sample further strengthens the suggestion of Fisher (2010), Lippman (2010) and Yang and Huang (2015) that different spatial layouts can impact on how teachers' and students' view and use technology.

Spatial effect on student perceptions of digital technology.

The analysis of responses to Scale C suggested a clear difference in how each group associated the affordances of their classroom with their perceived effectiveness of their device. The RM-ANOVAs (Table 6), supported by post hoc analysis (Table 7) indicated a clear and consistent significant time effect (learning space $\mathrm{x}$ time) between classes; 7.3 (NC) and $7.5(\mathrm{TC}), 8.2(\mathrm{NC})$ and $8.6(\mathrm{TC}), 8.3(\mathrm{NC})$ and $8.7(\mathrm{TC})$, and $8.5(\mathrm{NC})$ and 8.7 (TC). These differences suggested that the students who occupied an NGLS had a more favourable view of the impact of the space on the use of their device, than did their peers in a traditional layout.

The comparison of the between- and within-group analysis revealed an interesting trend about the longer-term occupation of an NGLS. The between-group analysis to Scale C 
presented a much stronger relationship between different spaces and its impact on student attitudes to digital technology than the within-group analysis. It is thought that over an extended period, the occupation of a classroom aligned with the affordances of digital technology appeared to allow teachers time to gain the self-efficacy to alter the manner they used technology (Ertmer \& Ottenbreit-Leftwich, 2010). Such a conclusion supports the suggestion of Fisher (2010) around the importance of the alignment between the space and technology to better support its effective utilisation.

Table 6.

Summary of Between-group RM-ANOVA Comparision of the NGLS Control and Traditional Student Perceptions about Digital Technology

\begin{tabular}{|c|c|c|c|c|c|c|c|c|c|c|c|c|}
\hline \multirow{2}{*}{ Class } & \multicolumn{4}{|c|}{ Incidence in Use } & \multicolumn{4}{|c|}{ Effectiveness } & \multicolumn{4}{|c|}{ Effect of Space } \\
\hline & MS & df & $\mathrm{F}$ & $\eta^{2}$ & MS & $\mathrm{df}$ & $\mathrm{F}$ & $\eta^{2}$ & MS & $\mathrm{df}$ & $\mathrm{F}$ & $\eta^{2}$ \\
\hline 7.3 vs. 7.5 & .01 & 1 & .01 & .00 & 1.59 & 1 & $8.75^{*}$ & .28 & 6.35 & 1 & $20.92 * *$ & .48 \\
\hline 7.4 vs. 7.6 & 1.48 & 1 & $15.42 * *$ & .36 & 10.86 & 1 & $17.73 * *$ & .39 & 8.89 & 1 & $11.58^{*}$ & .29 \\
\hline 8.2 vs. 8.6 & 5.25 & 1 & $17.58 * *$ & .24 & 32.00 & 1 & $68.23 * *$ & .55 & 52.41 & 1 & $151.31 * *$ & .73 \\
\hline 8.3 vs. 8.7 & 3.99 & 1 & 3.68 & .10 & 28.55 & 1 & $43.69 * *$ & .55 & 34.65 & 1 & $32.03 * *$ & .48 \\
\hline 8.4 vs. 8.7 & 8.92 & 1 & $11.81 * *$ & .23 & 14.12 & 1 & $17.14 * *$ & .30 & 17.26 & 1 & $13.27 *$ & .25 \\
\hline 8.5 vs. 8.7 & 9.99 & 1 & $13.78^{* *}$ & .29 & 27.73 & 1 & $34.38 * *$ & .50 & 27.84 & 1 & $23.70^{* *}$ & .41 \\
\hline
\end{tabular}

Table 7.

Post hoc Visual and Effect Size Between-group Comparison of the NGLS and Traditional Control Class Perceptions to Digital Technology as a Learning Tool

\begin{tabular}{ccccccccc}
\hline \multirow{2}{*}{$\begin{array}{c}\text { Groups } \\
\text { Compared }\end{array}$} & \multicolumn{2}{c}{ Incidence of Use } & & \multicolumn{2}{c}{ Effectiveness } & & \multicolumn{2}{c}{ Effect of Space } \\
\cline { 2 - 3 } & Visual & $g$ & & Visual & $g$ & & Visual & $g$ \\
\hline 7.3 vs. 7.5 & $N S^{a}$ & -0.01 & & $N S$ & +0.95 & & $S S^{b}$ & +1.29 \\
7.4 vs. 7.6 & $N S$ & +0.65 & & $N S$ & +0.68 & & $N S$ & +0.60
\end{tabular}




$\begin{array}{lllllll}8.2 \text { vs. } 8.6 & \text { NS } & +0.47 & \text { SS } & +1.05 & \text { SS } & +1.30 \\ 8.3 \text { vs. } 8.7 & \text { NS } & +0.29 & \text { SS } & +1.01 & \text { SS } & +0.96 \\ 8.4 \text { vs. } 8.7 & N S & +0.46 & \text { NS } & +0.59 & \text { NS } & +0.61 \\ 8.5 \text { vs. } 8.7 & \text { NS } & +0.56 & \text { SS } & +0.88 & \text { SS } & +0.85\end{array}$

Note. NGLS Control classes are listed first.

Note. ${ }^{a}$ Non-statistically significant visual effect. ${ }^{b}$ Statistically significant visual effect.

Teacher focus group.

A focus group was conducted to provide a contextual explanation of the quantitative findings. Fifteen of the 22 consenting teachers (Teachers A to J) participated.

There was little discussion around the incidence of the use of the device. Participants considered the device's high use to be relatively unaffected by the different layouts, thereby supporting the quantitative analysis of Scale A.

Some participants identified that the different spatial layouts had a significant effect on their use of technology. Teacher $\mathrm{C}$ highlighted that the "NGLS layout allowed me to use Tablet PC for other tasks, not just restricted to content delivery or presentation tool attached to the data projector." The shift away from the utilisation of their device as a content delivery tool was also supported by Teachers A, B, E, G, and I. Teacher B described how "in an NGLS I was less likely to have my Tablet connected to the data projector for the whole lesson. I found I only did this when my lesson intent dictated this type of approach.” Teacher E agreed by saying that the "multiple visual focal points allowed me to teach from different points each lesson." Teacher G identified that "increased movement, changed how I used the device. I was no longer tied to cable at the front of the room." Similar findings relating the polycentric layout to greater movement was found in the Byers and Imms $(2014,2016)$ studies. The conversation highlighted how teachers and students incorporated the use of the Tablet PCs with the visual focal points (TVs and additional whiteboards). Teacher D felt that unlike being tied "to the front of the room in the old classroom, the NGLS layout opened the 
whole room for the opportunity for learning to occur in multiple locations." Teacher H described that "the multiple focal points better facilitated collaborative group learning." While, Teacher I identified that the "multiple focal points gave the opportunity for greater differentiation. It allowed greater individual student focus." Interestingly through the focus group conversation, the participants appeared to integrate the digital and physical technologies into the same identity, as a visual display. Teacher choice appeared to be dictated by which technology best served their pedagogical intent.

The nature of teacher comments around the pedagogical use of digital technology and the physical layout of the learning environment supported the statistical analysis of Scales B and $\mathrm{C}$ from the LPTS survey. Teachers identified how the spatial affordances of the NGLS enabled them to use digital technologies in a manner that had a positive impact on student learning. Teachers' changed their use of all technologies (digital and physical) from primarily a content delivery tool to one that enabled more collaborative and responsive learning experiences. Collectively, this supports the suggestions by Lippman (2010) and Reynard (2009) that de-emphasis of the front fireplace teaching position can alter the pedagogical use of digital technologies.

\section{Conclusion}

This study evaluated the claim that different spaces enact different pedagogical uses of digital technology. Quantitative analysis of the quasi-experimental approach suggested that the different learning environments had a statistical impact on students' perceptions of the effectiveness of their Tablet PC, replicating the findings of the earlier Byers and Imms $(2014,2016)$ studies. Subsequent analysis of the teacher focus group suggested that these differences obtained from the quantitative analysis, stem from the greater alignment between the digital and spatial affordances of the NGLS. These findings support the suggestions by Fisher (2010), Lippman (2010) and Yang and Huang (2015) that the physical layout of the 
classroom can impact on the manner in which students and teachers use digital technology. The findings of this study provide further evidence that physical classroom layouts can act as a barrier to, or a conduit for, leveraging the potential of digital technologies with the aim of making them more effective pedagogically.

Not only has this study demonstrated the possible effect of different spaces on student attitudes to digital technology, but the successful replication has also further demonstrated the robustness and reliability of its methodology. The quasi-experimental approach facilitated by an SSRD accounted for and moderated some confounding variables. Its ability to generate empirical data evaluating the potential impact of different learning spaces has been shown in some studies (see Byers \& Imms, 2014, 2016). To further validate the approach, its methods and its means of analysis, further studies will be conducted in different contexts and sites. 


\section{Reference list}

Arbelaiz, A. M., \& Gorospe, J. M. C. (2009). Can the grammar of schooling be changed? Computers \& Education, 53(1), 51-56. doi:10.1016/j.compedu.2008.12.016

Baguley, T. (2012). Calculating and graphing within-subject confidence intervals for ANOVA. Behavior research methods, 44(1), 158-175. doi:10.3758/s13428-011-01237

Bigum, C., \& Rowan, L. (2008). Landscaping on shifting ground: teacher education in a digitally transforming world. Asia-Pacific Journal of Teacher Education, 36(3), 245255. doi:10.1080/13598660802232787

Bingimlas, K. A. (2009). Barriers to the successful integration of ICT in teaching and learning environments: A review of the literature. Eurasia Journal of Mathematics, Science \& Technology Education, 5(3), 235-245. doi:www.ejmste.com

Byers, T., \& Imms, W. (2014). Making the space for space: The effect of the classroom layout on teacher and student usage and perception of one-to-one technology. Paper presented at the 26th Australian Computers in Education Conference, Adelaide.

Byers, T., \& Imms, W. (2016). Evaluating the change in space in a technology-enabled primary years setting. In K. Fisher (Ed.), The translation design of schools: An evidence based approach to aligning pedagogy and learning environment design (pp. 215-236). The Netherlands: Sense.

Ertmer, P. A., \& Ottenbreit-Leftwich, A. T. (2010). Teacher technology change: How knowledge, confidence, beliefs, and culture intersect. Journal of Research on Technology in Education, 42(3), 255-284. doi:10.1080/15391523.2010.10782551

Fisher, K. D. (2004). Revoicing classrooms: A spatial manifesto. Forum, 46(1), 36-38. doi:10.2304/forum.2004.46.1.8 
Fisher, K. D. (2006). The new learning environment: Hybrid designs for hybrid learning. Retrieved from Melbourne:

http://www.woodsbagot.com/en/Documents/Public Research/PUBLIC2\%20The $\% 20$

\section{New\%20Learning\%20Environment.pdf}

Fisher, K. D. (2010). Technology-enabled active learning environments: An appraisal. Centre for Effective Learning Environments Exchange, 2010(7), 1-8.

doi:10.1787/5kmbjxzrmc0p-en

Lackney, J. A. (2008). Teacher environmental competence in elementary school environments. Children, Youth and Environments, 18(2), 133-159.

doi:www.colorado.edu/journals/cye

Lippman, P. C. (2010). Can the physical environment have an impact on the learning environment? CELE Exchange. Centre for Effective Learning Environments, 2010(11-14), 1-5. doi:10.1787/5km4g21wpwr1-en

Peugh, J. L., \& Enders, C. K. (2004). Missing data in educational research: A review of reporting practices and suggestions for improvement. Review of Educational Research, 74(4), 525-556. doi:10.3102/00346543074004525

Reynard, R. (2009). Designing learning spaces for instruction, not control. Campus Technology. Retrieved from

http://campustechnology.com/articles/2009/04/29/designing-learning-spaces-for$\underline{\text { instruction-not-control.aspx }}$

Selwyn, N. (2010). Schools and schooling in the digital age: A critical analysis. New York: Routledge.

Tamim, R. M., Lowerison, G., Schmid, R. F., Bernard, R. M., \& Abrami, P. C. (2011). A multi-year investigation of the relationship between pedagogy, computer use and 
course effectiveness in postsecondary education. Journal of Computing in Higher Education, 23(1), 1-14. doi:10.1007/s12528-010-9041-4

Tyack, D., \& Tobin, W. (1994). The "grammar" of schooling: Why has it been so hard to change? American Educational Research Journal, 31(3), 453-479. doi:10.3102/00028312031003453

Yang, J., \& Huang, R. (2015). Development and validation of a scale for evaluating technology-rich classroom environment. Journal of Computers in Education, 2(2), 145-162. doi:10.1007/s40692-015-0029-y 